\title{
miR-218 suppresses the proliferation of osteosarcoma through downregulation of E2F2
}

\author{
CHENGMIN XUAN $^{1,2^{*}}$, MINGWEI JIN ${ }^{1 *}$, YONG GAO $^{2,3^{*}}$, SHUMEI XU ${ }^{1}$, \\ LEI WANG $^{1}$, YUAN WANG ${ }^{1}$, RUI HAN ${ }^{1}$ and QI AN ${ }^{1,2}$ \\ ${ }^{1}$ Department of Hematology, Xuzhou Children's Hospital, Xuzhou, Jiangsu 221006; \\ ${ }^{2}$ Department of Clinical Medicine, The Graduate School, Xuzhou Medical College, Xuzhou, Jiangsu 221004; \\ ${ }^{3}$ Department of Neurosurgery, Xinyi People's Hospital, Xinyi, Jiangsu 221400, P.R. China
}

Received August 5, 2016; Accepted September 4, 2018

DOI: $10.3892 / \mathrm{ol} .2018 .9576$

\begin{abstract}
Osteosarcoma is the most common primary malignant bone tumor type in children and adolescents under 20 years of age. Biological characteristics include invasiveness, metastasis, abnormal differentiation and loss of contact inhibition. microRNAs (miRNAs) are involved in the transcriptional and post-transcriptional regulation of target mRNAs. Previous studies have demonstrated that miR-218 inhibits tumor formation and progression in glioma, colon cancer and renal cell carcinoma; however, the mechanism of action of miR-218 in osteosarcoma has not been completely determined. In the present study, it was demonstrated that miR-218 exhibited low expression and targeted E2F2 in osteosarcoma cells. Additionally, overexpression of miR-218 inhibited osteosarcoma cell proliferation, with the opposite result occurring following the knockdown of miR-218. Furthermore, it was determined that miR-218 inhibited tumor formation and reduced the expression of E2F2 and proliferating cell nuclear antigen in nude mice. Collectively, the present data demonstrated that miR-218 serves an important role in suppressing the proliferation of osteosarcoma cells, potentially regulated by E2F2, which may provide a novel protein marker for the treatment of osteosarcoma.
\end{abstract}

\section{Introduction}

Of all pediatric bone malignant tumor types, osteosarcoma has the highest incidence (1). Although surgical techniques and chemotherapy have improved, the treatment effects remain

Correspondence to: Dr Qi An, Department of Hematology, Xuzhou Children's Hospital, 18 Su-di Road, Xuzhou, Jiangsu 221006, P.R. China

E-mail: dranqi@126.com

${ }^{*}$ Contributed equally

Key words: microRNA-218, proliferation, E2F2, microRNAs, osteosarcoma, children unchanged in detectable metastatic osteosarcoma $(2,3)$. The rapid growth of metastases and chemotherapy resistance are the primary causes of not achieving complete remission (4); thus, it is vital to investigate an early detection marker and molecular target in order to achieve complete remission of osteosarcoma.

MicroRNAs (miRNAs) regulate protein expression through complementary base pairing to specific mRNAs that act in the 3'-untranslated regions (3'-UTRs) of target mRNAs (5). miRNAs serve an irreplaceable role in a variety of biological processes in cancer development and progression, including differentiation, proliferation metastasis and apoptosis (6-9). Previous studies have demonstrated that miR-218 is associated with the proliferation, migration and invasion of osteosarcoma $(10,11)$; however, there is limited knowledge regarding the role that miR-218 serves in the proliferation of osteosarcoma. Therefore, the molecular mechanism underlying the action of miR-218 in osteosarcoma was investigated.

E2F2 is affiliated with a family of transcription factors that includesE2F1-8(12). Studies have demonstrated that E2Ffactors are, not only involved in the expression of cell cycle-associated genes, but also in the expression of differentiation-, apoptosis-, autophagy- and metabolism-associated genes (13-15). Previously, E2F2 was determined to maintain $\mathrm{G}_{0}$ arrest by regulating cell cycle-associated genes (13). In the present study, whether E2F2 was essential for osteosarcoma tumorigenesis was investigated.

In brief, the present results demonstrated that miR-218 inhibits the proliferation of human osteosarcoma cells through $\mathrm{E} 2 \mathrm{~F} 2$, and that E2F2 promotes osteosarcoma tumorigenesis.

\section{Materials and methods}

Antibodies. Anti-E2F2 (dilution, 1:500; cat. no. sc-633) antibodies and $\beta$-actin (dilution, 1:1,000; cat. no. sc-58673) were obtained from Santa Cruz Biotechnology, Inc. (Dallas, TX, USA). Secondary antibodies anti-mouse IgG, (dilution, 1:2,000; cat. no. 7076) were obtained from Cell Signaling Technology, Inc. (Danvers, MA, USA).

Cell culture. 293, Human osteoblast hFOB1.19 and human osteosarcoma MG63 cell lines were obtained from the 
Shanghai Institute of Cell Biology, Chinese Academy of Sciences (Shanghai, China), and maintained at $37^{\circ} \mathrm{C}$ in an atmosphere containing $5 \% \mathrm{CO}_{2}$ in Dulbecco's modified Eagle's medium, D-MEM/F-12 medium and Minimum Eagle's medium, respectively, and with $10 \%$ heat-inactivated fetal bovine serum (HyClone; GE Healthcare Life Sciences, Logan, UT, USA).

Constructs and production of lentivirus. The miR-218 complementary DNA (cDNA) sequences were inserted between the $B a m \mathrm{HI} / M l u \mathrm{I}$ restriction sites in the pGLV3/H1 vector (0.03 pmol) (Shanghai GenePharma Co., Ltd., Shanghai, China). The miR-218 short-hairpin RNA (shRNA) oligomer (target sequence: 5'-GATCCACATGGTTAGATCAAGCAC AACGATACATGGTTAGATCAAGCACAAACCGGTACA TGGTTAGATCAAGCACAATCACACATGGTTAGATCA AGCACAATTTTTTG-3') was subcloned into the pGLV3/H1 construct between the BamHI-MluI restriction sites. MG63 cells were constructed using the three-plasmid lentivirus system, where the second-generation lentiviral packaging, pspax2, and viral envelope, pMD2G (Shanghai GenePharma Co., Ltd.) were co-transfected in 293 cells using PolyJet (SignaGen Laboratories, Rockville, MD, USA), according to the manufacturer's protocols, to package the viruses. The above three plasmids (pspax2: pMD2G: pGLV3/H1-miR-218=1 ug: 1 ug: 2 ug), opti-MEM (500 ul) and PolyJet (12 ul) were mixed and allowed to stand for $20 \mathrm{~min}$. It was subsequently added to a six-well plate with MG63 cell density of 70\%. After $12 \mathrm{~h}$, the medium was changed, and the supernatant, containing lentivirus, was collected for $72 \mathrm{~h}$.

Establishment of stable cell lines. For overexpression of miR-218, the MG63 cells were infected by green fluorescent protein (GFP) positive miR-218 viruses. Following $48 \mathrm{~h}$ of infection, the cells were cultured in Minimum Eagle's Medium containing $2.5 \mathrm{lg} / \mathrm{ml}$ puromycin (Thermo Fisher Scientific, Inc., Waltham, MA, USA). The surviving cells were cultured into cell lines stably expressing miR-218. The control, expressing GFP, and miR-218-sponge, expressing GFP, groups were obtained according to the methods described above.

Reverse transcription-quantitative polymerase chain reaction (RT-qPCR). cDNA was obtained using mRNA RT (Roche Diagnostics, Basel, Switzerland), according to the manufacturer's protocol. qPCR was performed using an ABI 7300 real-time PCR instrument (Applied Biosystems; Thermo Fisher Scientific, Inc.) with FastStart Universal SYBR ${ }^{\circledR}$ Green Mix (Roche Diagnostics, Basel, Switzerland), according to the manufacturer's protocols. The primers for the amplification of E2F2 and $\beta$-actin were as follows: E2F2 forward, 5'-AGCTGG ATCTGGAGGGGATT-3' and reverse, 5'-AGGACCCCATCC TCTGACTC-3'; and $\beta$-actin forward, 5'-CATGTACGTTGC TATCCAGGC-3' and reverse, 5'-CGCTCGGTGAGGATC TTCATG-3'. The molecular weights were 196 and 195 bp, respectively. Thermocycling protocol included pre-denatured at $95^{\circ} \mathrm{C}$ for $3 \mathrm{~min}$, denaturation at $95^{\circ} \mathrm{C}$ for $15 \mathrm{sec}$, annealing at $60^{\circ} \mathrm{C}$ for $15 \mathrm{sec}$ and extension at $72^{\circ} \mathrm{C}$ for $1 \mathrm{~min}$ for 40 cycles. Expression levels were quantified using the $2^{-\Delta \Delta C q}$ method (16).
EdU experiment. The EdU incorporation assay (5-ethynyl-2'-deoxyuridine; Guangzhou RiboBio Co., Ltd., Guangzhou, China) was used to evaluate the number of proliferating cells. A total of $1 \times 10^{4}$ cells, MG63/control, MG63/miR-218 and MG63/miR-218-sponge cells, were plated in 96-well plates and cultured for an additional $24 \mathrm{~h}$. Cells were treated with $50 \mu \mathrm{M}$ EdU for $2 \mathrm{~h}$ at $37^{\circ} \mathrm{C}$ and then fixed with $4 \%$ formaldehyde for $30 \mathrm{~min}$ at room temperature. Subsequently, $2 \mathrm{mg} / \mathrm{ml}$ glycine antagonized formaldehyde and $0.5 \%$ Triton X-100 was added and incubated for $15 \mathrm{~min}$ at room temperature. Following this, $100 \mu 1 \mathrm{XX}$ Apollo reaction cocktail (Guangzhou RiboBio Co., Ltd.) and DAPI dye were added to the cells and incubated for $30 \mathrm{~min}$ at room temperature, respectively. Images were obtained using the fluorescent Olympus IX-71 inverted microscope (magnification, x200; Olympus Corporation, Tokyo, Japan).

Flow cytometry. Cells $\left(1 \times 10^{5}\right)$ were plated in 6-well plates and cultured for $24 \mathrm{~h}$ at $37^{\circ} \mathrm{C}$. The cells were digested using trypsin and single suspension cells were collected in $1.5 \mathrm{ml}$ Eppendorf tubes. Subsequently, the cells were treated with $70 \%$ ethanol for $15 \mathrm{~min}$ at $0^{\circ} \mathrm{C}$ and then incubated with RNase for $30 \mathrm{~min}$ at $37^{\circ} \mathrm{C}$. Following this, the cells were dyed with propidium iodide (10 ug $/ \mathrm{ml}$; Thermo Fisher Scientific, Inc.) and protected from light for $30 \mathrm{~min}$ at room temperature. Cells were then subjected to flow cytometry with a flow cytometer and the results were analyzed through CellQuest Pro 4.0.2 software (BD Biosciences, Franklin Lakes, NJ, USA).

Plate colony formation. A total of $2 \times 10^{2}$ cells, MG63/control, MG63/miR-218 and MG63/miR-218-sponge cells, were plated in 6-cm dishes and cultured for 14 days at $37^{\circ} \mathrm{C}$. Cells were fixed with $4 \%$ formaldehyde for $30 \mathrm{~min}$ and then incubated with $0.05 \%$ crystal violet for $30 \mathrm{~min}$ at room temperature. Images were captured using a Canon 70D camera (Canon, Inc., Tokyo, Japan). Colonies with $>50$ cells were counted.

Bioinformatics prediction. The miR-218 target prediction was performed using bioinformatics algorithms from TargetScan 6.2 (http://www.targetscan.org/) and PicTar (http://pictar.mdc-berlin.de/).

Western blot analysis. Cell protein was extracted from the osteosarcoma cell lines by bicinchoninic acid protein assay kit (Beyotime Institute of Biotechnology Co., Ltd., Shanghai, China), according to the manufacturer's protocols. Equivalent amounts (40 ug) of protein were added to 10\% SDS-PAGE and then transferred to polyvinylidene fluoride (PVDF) membranes (EMD Millipore, Billerica, MA, USA) using a wet transfer method, where the PAGE gel and PVDF membranes are placed in a thermostat covered with ice with a constant current of $225 \mathrm{~mA}$ for $2.5 \mathrm{~h}$ at $0^{\circ} \mathrm{C}$. Following blocking with $5 \%$ skimmed milk powder overnight at $4^{\circ} \mathrm{C}$, the primary antibodies (E2F2 and $\beta$-actin) were added and incubated at $4^{\circ} \mathrm{C}$ overnight. Subsequently, the secondary antibody was added and incubated for $2 \mathrm{~h}$ at room temperature. The Pierce enhanced chemiluminescent Plus Western Blotting Substrate (Thermo Fisher Scientific, Inc.) was added to PVDF membranes and images were obtained using Image Lab 5.2 (Bio-Rad, Laboratories, Inc. Hercules, CA, USA). Results were 


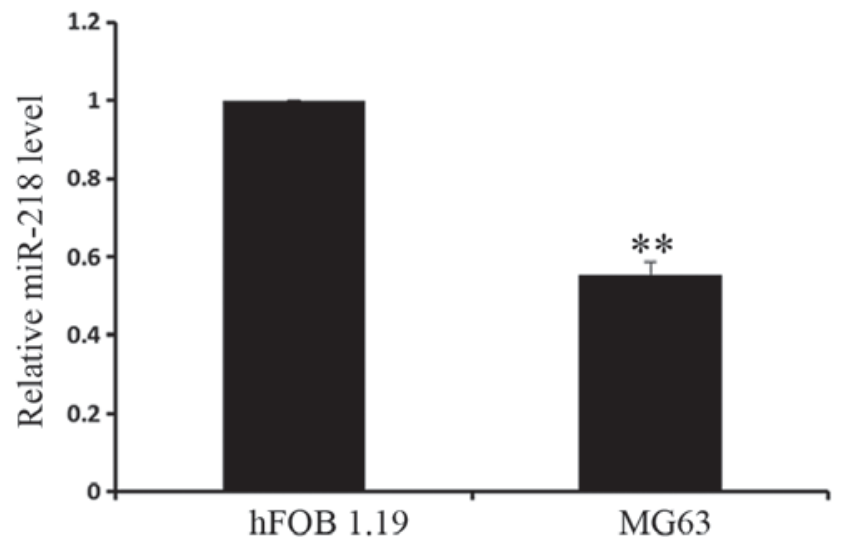

Figure 1. Expression level of miR-218 in human osteosarcoma cells. Total complementary DNA from osteoblastic hFOB1.19 and osteosarcoma MG63 cell lines were analyzed for the expression of miR-218 using reverse transcription-quantitative polymerase chain reaction. ${ }^{* *} \mathrm{P}<0.01$ compared with hFOB1.19. miR, microRNA.

analyzed using ImageJ 1.8.0 software (National Institutes of Health, Bethesda, MD, USA).

Luciferase reporter experiments. E2F2 3'UTR was subcloned between the $S a c \mathrm{I} / \mathrm{XboI}$ restriction sites in the pmirGLO vector (Shanghai GenePharma Co., Ltd.). The pmirGLO-MT-BMI1 3'UTR plasmid was constructed by removing the binding site for miR-218 (UUCGUGUU). PmirGLO-WT-E2F2 3'UTR/pmirGLO-MT-E2F2 3'UTR and phRL-TK were co-transfected into MG63 cells using Polyjet. Luciferase activity was assessed using the Dual-Luciferase Reporter Assay system (Promega Corporation, Madison, WI, USA) $36 \mathrm{~h}$ after transfection. Luciferase activity was normalized to Renilla luciferase activity.

Animal experiments. Female BALB/c nude mice $(n=6$; $\sim 20 \mathrm{~g}$ ), 4-5 weeks of age, were purchased from Charles River Laboratories, Inc. (Wilmington, MA, USA). The mice were housed in a pathogen-free plastic cage with a sealed air filter, at room temperature $\left(26-28^{\circ} \mathrm{C}\right)$ and relative humidity of $40-60 \%$. Mice had access to drinking water and fed with an autoclaved diet and were under a 10/14 h light/dark cycle, respectively. Following corresponding lentivirus infection of MG63 cells, the corresponding cell lines, MG63/control, MG63/miR-218 and MG63/miR-218-sponge cells, was obtained. A total of $2 \times 10^{6}$ cells $/ 0.1 \mathrm{ml} \mathrm{MG63/control,} \mathrm{MG63/miR-218} \mathrm{and}$ MG63/miR-218-sponge cells in phosphate saline were injected subcutaneously into the lower back of nude mice. After eight weeks, nude mice were sacrificed by intraperitoneal injection of pentobarbital sodium (150 to $200 \mathrm{mg} / \mathrm{kg}$ ), in accordance with the guidelines for laboratory animals established by and approved by the Xuzhou Children's Hospital Animal Care and Use Committee. The tumors were measured by mean as follows: Volume $=($ length $\mathrm{x}$ width 2$) / 2)$.

Immunohistochemistry. Immunohistochemistry experiments were performed using the S-P immunohistochemistry kit (OriGene Technologies, Inc., Rockville, MD, USA). The $4 \%$ paraformaldehyde fixed paraffin sections (4 micron) were deparaffinized in xylene for $5 \mathrm{~min}$ and rehydrated in graded ethanol $(100,95,85$ and $75 \%)$ at room temperature for 5 min per step. Subsequently, antigen retrieval was conducted by heating sections in citric buffer (Sigma-Aldrich; Merck KGaA, Darmstadt, Germany) in a pressure cooker at $120^{\circ} \mathrm{C}$. Endogenous peroxidase activity was blocked in $3 \%$ hydrogen peroxide at room temperature for $30 \mathrm{~min}$. Sections were incubated with $2.5 \%$ bovine serum albumin (BSA; Sigma-Aldrich; Merck KGaA) to reduce non-specific binding at room temperature for $10 \mathrm{~min}$. Anti-proliferating cell nuclear antigen antibodies at 1:100 dilution in 2.5\% BSA (PBS as control) were incubated at room temperature for $1 \mathrm{~h}$ and then incubated with biotin-conjugated goat anti-rabbit IgG (cat. no. ZB-2010; Zhongshan Goldenbridge Biotech Co.) and horseradish peroxidase-conjugated streptavidin (cat. no. AR100017; OriGene Technologies, Inc.) at room temperature for $20 \mathrm{~min}$. Staining was performed by incubating sections for 2-10 min with the chromogenic reagent 3,3'-diaminobenzidine (DAB) followed by quenching of the reaction with water. Sections were analyzed according to the degree of color, as longer periods of incubation resulted to darker background color for analysis. Hematoxylin was used as the counterstain for cell nuclei for $2 \mathrm{~min}$ and then sections were dehydrated using graded ethanol (100, 95, 85 and 75\%) and xylene at room temperature. Images were captured using an fluorescent Olympus IX-71 inverted microscope (magnification, $\mathrm{x} 400$ ).

Statistical analysis. SPSS 13.0 software (SPSS, Inc., Chicago, IL, USA) was used to perform the statistical analyses. Results are shown as the mean \pm standard error of the mean. Statistical significance was analyzed using the Student's t-test (two groups) and one-way analysis of variance (multiple groups) and Dunnett's post hoc test. $\mathrm{P}<0.05$ was considered to indicate a statistically significant difference.

\section{Results}

miR-218 expression is attenuated in osteosarcoma cells. To determine the expression level of miR-218, it was examined in the osteoblastic cell line hFOB1.19 and the osteosarcoma cell line MG63 using RT-qPCR. It was determined that miR-218 had significantly increased expression in osteoblasts, compared with osteosarcoma cells (Fig. 1). The present results demonstrated that miR-218 serves an important role in osteosarcoma tumorigenesis, which provides preliminary evidence for future research.

miR-218 inhibits proliferation of osteosarcoma cells. To further investigate the molecular mechanism underlying miR-218 in osteosarcoma cells, a miR-218 overexpressing cell line was constructed using lentiviral infection and also miR-218 was knocked down in MG63 cells using shRNA specific for miR-218 (Fig. 2A). miR-218 expression was verified using RT-qPCR (Fig. 2B). To observe the results of altering the expression of miR-218 in MG63 cells, the cell cycle was analyzed using flow cytometry. Control cells had the following distribution of cell cycle phases: $46.47 \%$ in $\mathrm{G}_{1} ; 39.02 \%$ in $\mathrm{S}$ and $14.50 \%$ in $\mathrm{G}_{2} / \mathrm{M}$. miR-218-overexpressing cells had the following distribution of cell cycle phases: $65.58 \%$ in $\mathrm{G}_{1}$, $13.39 \%$ in $\mathrm{S}$ and $21.03 \%$ in $\mathrm{G}_{2} / \mathrm{M}$. miR-218-knockdown cells 
A
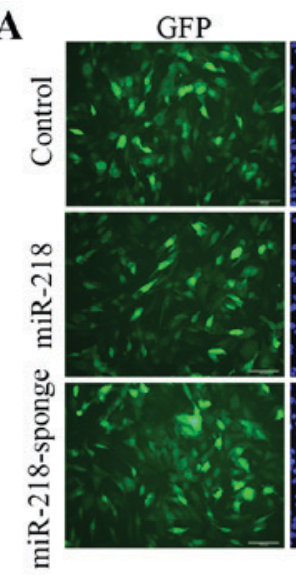

C

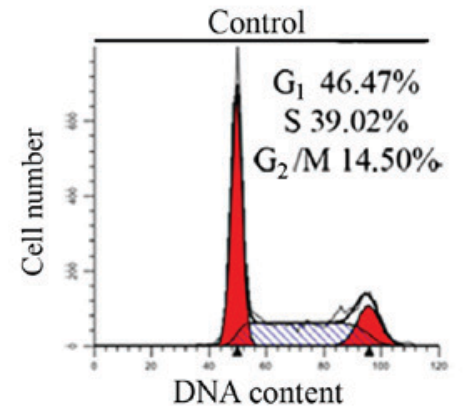

D
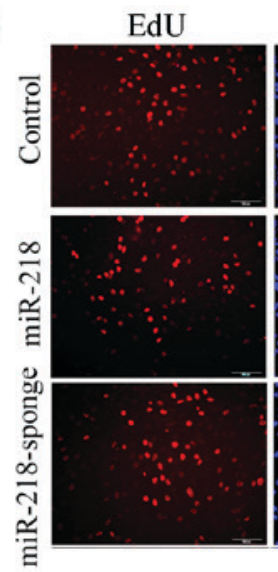

$\mathbf{F}$

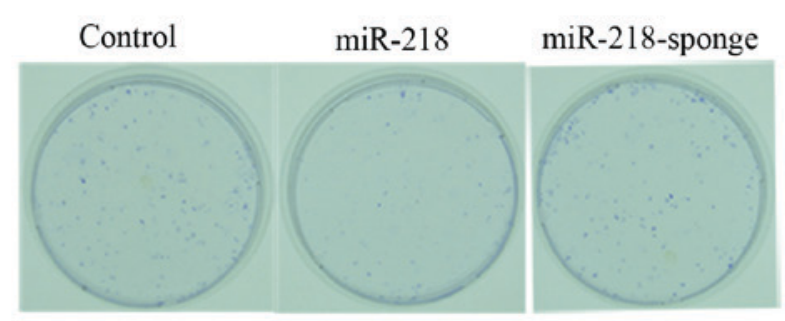

B

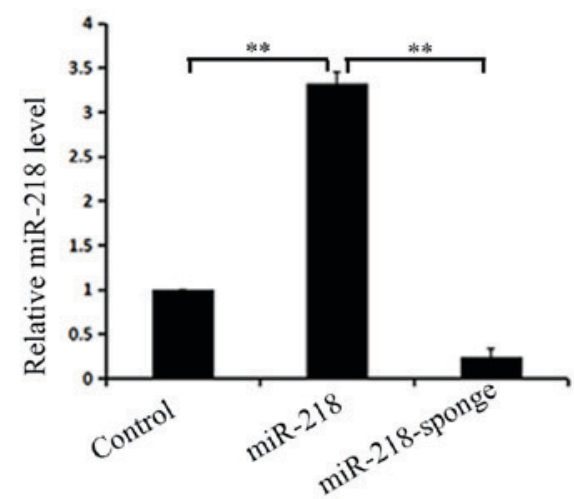

$\operatorname{miR}-218$
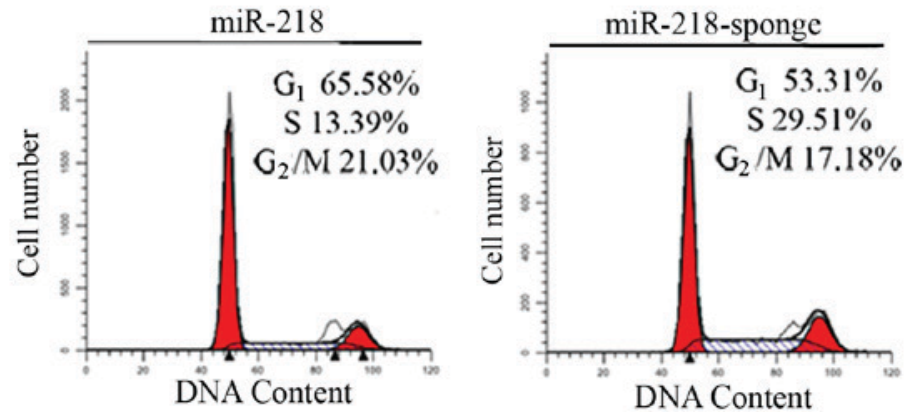

$\mathbf{E}$

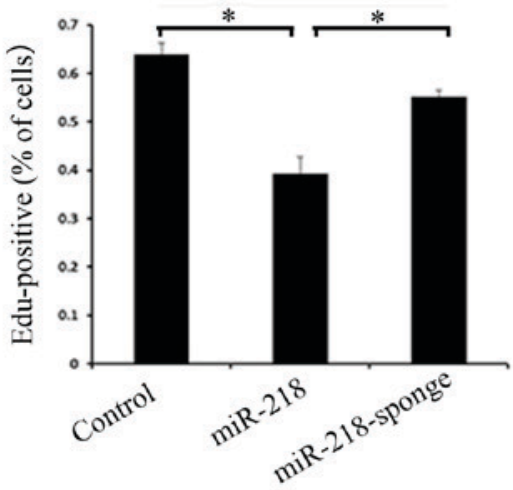

G

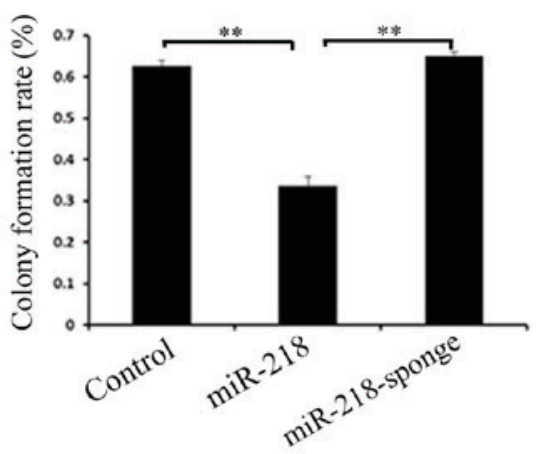

Figure 2. miR-218 significantly decreased the ability of osteosarcoma cells to proliferate. (A) GFP images displaying control, miR-218 and miR-218-sponge expressing stable MG63 cell lines. Scale bar, $100 \mu \mathrm{m}$; magnification, x200. (B) Expression of miR-218 was verified using reverse transcription-quantitative polymerase chain reaction. (C) The cell cycle was analyzed using flow cytometry. (D) The number of proliferating cells in the stable cell lines using the EdU proliferation assay. Scale bar, $100 \mu \mathrm{m}$; magnification, x200. (E) Statistical analysis of the EdU proliferation experiments. (F) Plate colony formation depicting the colony formation ability of the stable cell lines. (G) Statistical analysis of the colony formation experiments. GFP, green fluorescent protein; miR, microRNA. " $\mathrm{P}<0.05$ and ${ }^{* *} \mathrm{P}<0.01$ compared with control and miR-218 group; and miR-218 and miR-218-sponge group.

had the following distribution of the cell cycle phases: $53.31 \%$ in $\mathrm{G}_{1}, 29.51 \%$ in $\mathrm{S}$ and $17.18 \%$ in $\mathrm{G}_{2} / \mathrm{M}$ (Fig. 2C). Similar results were obtained using EdU proliferation $(\mathrm{P}=0.016)$ and colony formation assays $(\mathrm{P}=0.001)$, and demonstrated 


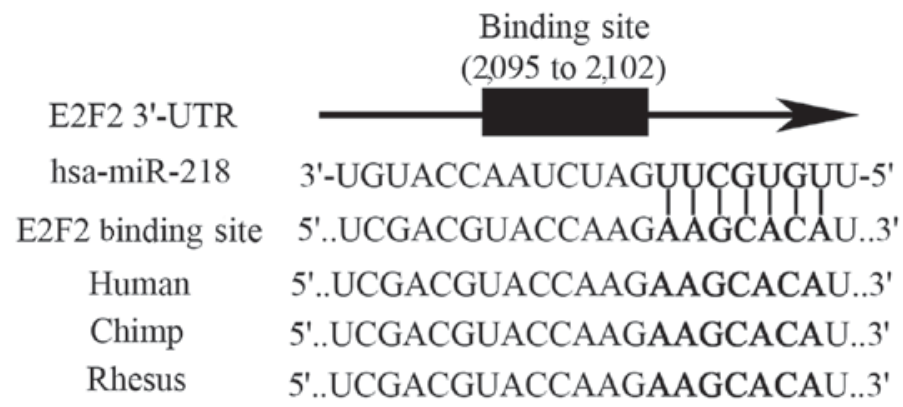

B

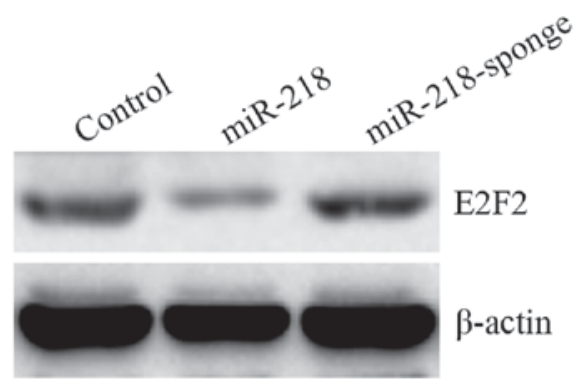

$\mathrm{C}$

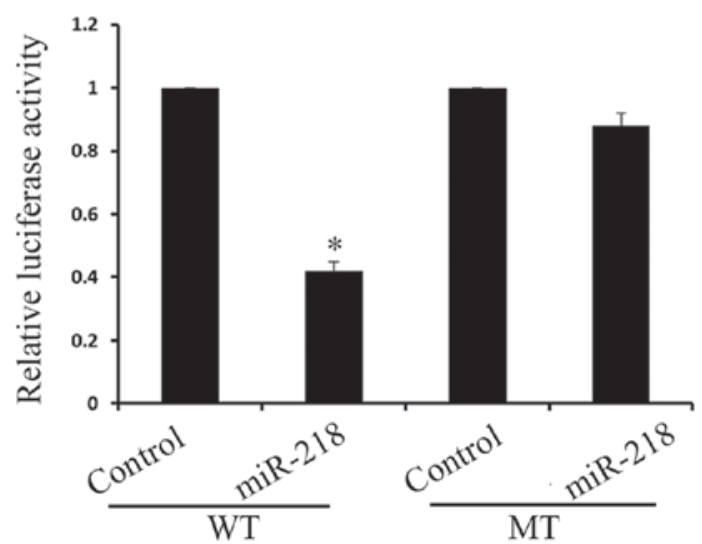

Figure 3. E2F2 is the target of miR-218 in human osteosarcoma cells. (A) Putative binding sites of miR-218 within the E2F2 3'UTR, as predicted using TargetScan and Pictar algorithm software. Bold letters represent the site of action. (B) Expression of E2F2 was verified using western blotting of protein lysates from the stable cell lines. (C) miR-218 decreased luciferase levels in MG63 cells expressing WT E2F2 3'UTR compared with the control group; however, luciferase levels increased in MG63 cells expressing MT E2F2 3'UTR compared with the control group. miR, microRNA; UTR, untranslated region; WT, wild-type; MT, mutant. "P $<0.05$ vs. control group and miR-218 group.

that overexpression of miR-218 inhibited proliferation and silencing of miR-218 promoted proliferation (Fig. 2D-G).

E2F2 is a direct target of $m i R-218$. To study the mechanism underlying miR-218 inhibition of osteosarcoma proliferation, a bioinformatics software was used to demonstrate that miR-218 directly targeted the E2F2 3'UTR (Fig. 3A). The expression of E2F2 was significantly increased following overexpression of miR-218, as indicated by western blot analysis, and expression of E2F2 was increased following silencing of miR-218 (Fig. 3B). Furthermore, pmirGLO-WT-E2F2 3'UTR and pmirGLO-MT-E2F2 3'UTR plasmids were constructed and the luciferase activity in the pmirGLO-WT-E2F2 3'UTR group was determined to be significantly decreased, compared with the control group, while there was no difference between the control and the pmirGLO-MT-E2F2 3'UTR groups (Fig. 3C).

miR-218 inhibits tumor formation in vivo. Finally, the in vivo role miR-218 serves in osteosarcoma tumorigenicity in nude mice was investigated. After eight weeks, nude mice were sacrificed and their tumors were measured. Tumor sizes of mice injected with MG63 cells expressing miR-218 were reduced $(\mathrm{P}=0.001)$ and had a reduced growth rate, compared with mice injected with control or miR-218 sponge cells $(\mathrm{P}=0.001)$ (Fig. 4A and $\mathrm{B})$. Immunohistochemistry also confirmed that overexpression of miR-218 inhibited proliferation and silencing of miR-218 promoted proliferation $(\mathrm{P}=0.001)$ (Fig. 4C and D). Western blot analysis of tumor tissues derived from mice receiving different treatments also confirmed that E2F2 was significantly downregulated in the
miR-218 overexpressing group, compared with the control group, and that E2F2 was significantly upregulated in the miR-218 knockdown group, compared with the miR-218 overexpressing group ( $\mathrm{P}=0.02)$ (Fig. $4 \mathrm{E}$ and $\mathrm{F}$ ).

In conclusion, the present results indicated that miR-218 suppresses the proliferation of human osteosarcoma cells through E2F2 and E2F2 is a direct target of miR-218.

\section{Discussion}

Previous studies demonstrated that miR-218 suppressed the migration and invasion in osteosarcoma cells (11); however, research on the role of miR-218 in proliferation has not been reported for osteosarcoma cells. In the present study, it was determined that miR-218 exhibited reduced expression in osteosarcoma cells, compared with osteoblasts. miR-218 may serve a tumor suppressor role in osteosarcoma. To investigate the exact role of miR-218 in osteosarcoma cells, vectors used to upregulate and downregulate the expression of miR-218 in human osteosarcoma MG63 cells were constructed using the three-plasmid lentivirus system. The results demonstrated that miR-218 suppresses the proliferation of human osteosarcoma cells through E2F2 in vitro and in vivo and E2F2 is a direct target of miR-218.

Numerous studies have demonstrated that miR-218 can be regarded as a tumor suppressor in a number of cancer types, including esophageal carcinoma (17), hepatocellular carcinoma (18), lung carcinoma (19), pancreatic cancer (20), glioma (21) and prostate cancer (22). It has been reported that miR-218 can also be regarded as a tumor suppressor in osteosarcoma (11), 
A

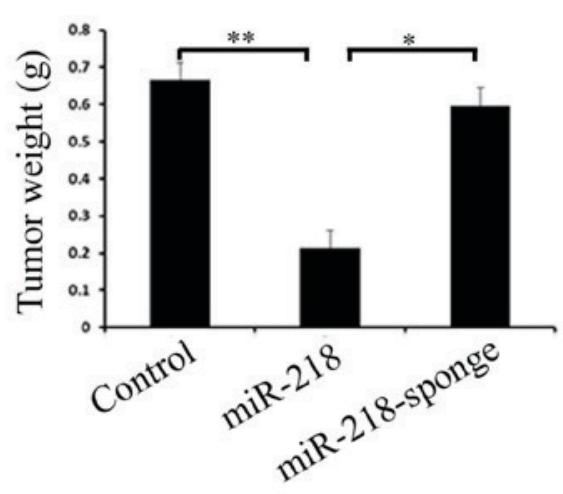

C
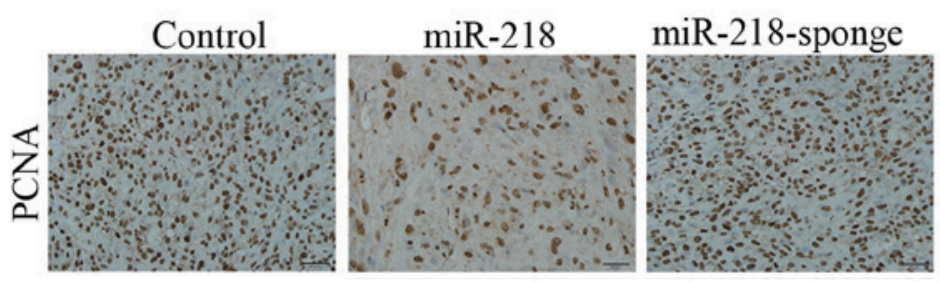

B

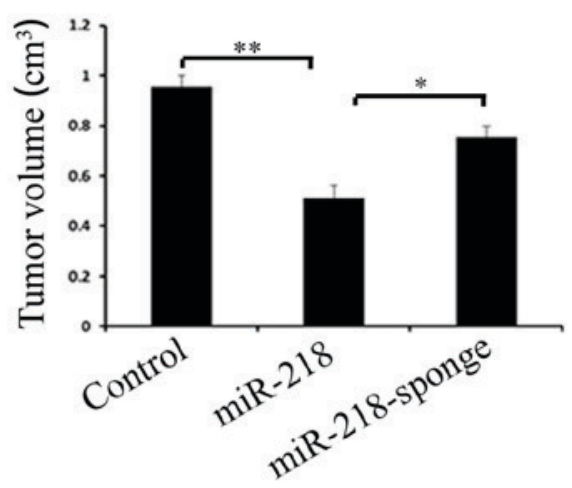

D

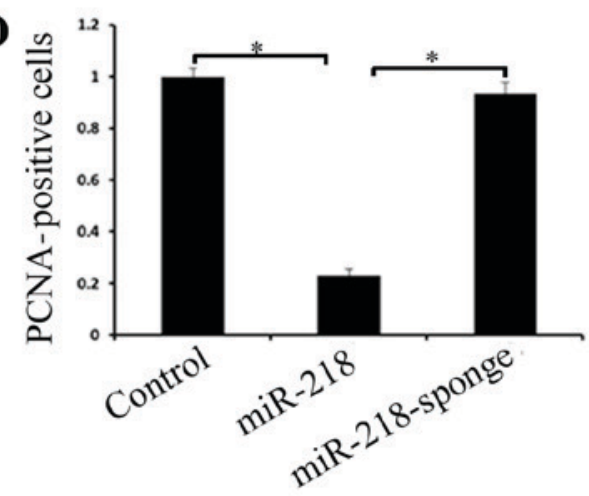

$\mathbf{F}$

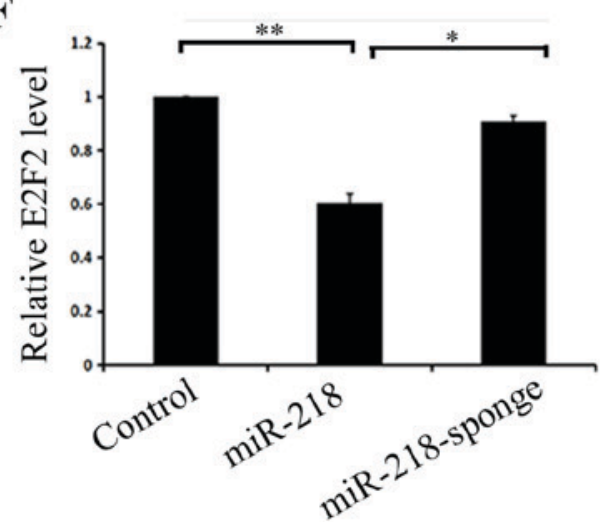

Figure 4. miR-218 inhibits the tumorigenicity of human osteosarcoma cells in vivo. (A) Statistical analysis of mean tumor weight calculated as follows: Weight=(weight1+weight2+weight3)/3. (B) Statistical analysis of tumor volume. (C) Representative images depicting PCNA-positive cells (scale bar, $20 \mu$ m; magnification, $\mathrm{x}$ 400). (D) Statistical analysis of the PCNA index. (E) Expression of E2F2 was verified using western blotting of tumor tissues from nude mice. (F) Quantification of relative expression level of E2F2 in miR-218, miR-218-sponge and control groups. miR, microRNA; PCNA, proliferating cell nuclear antigen. " $\mathrm{P}<0.05$ and ${ }^{* *} \mathrm{P}<0.01$ compared with control group and miR-218 group; miR-218 and miR-218-sponge group.

which is consistent with the present data. In a previous study, expression of miR-218 was significantly reduced in osteosarcoma tissues, compared with non-tumorous tissues (10). In agreement with that report, it was determined that miR-218 was expressed at a reduced level in osteosarcoma, compared with osteoblast cells. Previous studies demonstrated that miR-218 may serve a role in tumor suppression through targeting BMI1 (17,23), RET (18), tumor protein D52 (22), KIT (24) and SH3 domain-containing growth factor receptor bound protein 2-like protein 1 (25). Furthermore, it was determined that miR-218 directly targeted the E2F2 3'UTR in osteosarcoma.

$\mathrm{E} 2 \mathrm{~F} 2$ is a member of the E2F transcription factor family, which serves a central role in the regulation of cell cycle progression $(13,26,27)$. E2F2 may serve the role of a promoter of tumorigenesis. A number of recent studies support this point, reporting that $\mathrm{E} 2 \mathrm{~F} 2$ is a pivotal member in promoting the proliferation of osteosarcoma (26), human glioblastoma (28) and hepatocellular carcinoma cells (29); however, in contrast to these data, E2F2 suppresses the proliferation of renal carcinoma (30) and colon carcinoma cells (31). In the present study, it was indicated that the downregulation of E2F2 suppressed the proliferation of human osteosarcoma cells by overexpressing miR-218 and that upregulation of E2F2 promoted the proliferation of human osteosarcoma cells by silencing miR-218. Thus, it was confirmed that $\mathrm{E} 2 \mathrm{~F} 2$ promotes osteosarcoma tumorigenesis.

In conclusion, it was determined that miR-218 had reduced expression in osteosarcoma cells, inhibiting the proliferation through targeting E2F2 directly, and E2F2 can promote osteosarcoma tumorigenesis. This result may be significant in the early detection of osteosarcoma, which could have treatment 
implications and could be a valuable protein marker in the early detection of osteosarcoma in children.

\section{Acknowledgements}

Not applicable.

\section{Funding}

The present study was supported by Xuzhou Municipal Bureau on Science and Technology (grant no. XM12B055).

\section{Availability of data and materials}

All data generated or analyzed during this study are included in this published article.

\section{Authors' contributions}

CX, MJ, and YG proposed the concept and design of the study. $\mathrm{CX}, \mathrm{YG}, \mathrm{RH}$ and QA performed experiments, prepared all figures, tables and manuscript. SX applied biology software predicts target genes for miRNAs. LW and YW performed the data and figure analysis.

\section{Ethics approval and consent to participate}

The present study was approved by the Ethics Committee of Xuzhou Children's Hospital.

\section{Patient consent for publication}

Not applicable.

\section{Competing interests}

The authors declare that they have no competing interests.

\section{References}

1. Sakamoto A and Iwamoto Y: Current status and perspectives regarding the treatment of osteo-sarcoma: Chemotherapy. Rev Recent Clin Trials 3: 228-231, 2008.

2. Mori K, Rédini F, Gouin F, Cherrier B and Heymann D: Osteosarcoma: Current status of immunotherapy and future trends (Review). Oncol Rep 15: 693-700, 2006.

3. Loeb DM: Is there a role for immunotherapy in osteosarcoma? Cancer Treat Res 152: 447-457, 2009.

4. Habel N, Hamidouche Z, Girault I, Patiño-García A, Lecanda F, Marie PJ and Fromigué O: Zinc chelation: A metallothionein $2 \mathrm{~A}$ 's mechanism of action involved in osteosarcoma cell death and chemotherapy resistance. Cell Death Dis 4: e874, 2013.

5. Yanokura M, Banno K, Kobayashi Y, Kisu I, Ueki A, Ono A, Masuda K, Nomura H, Hirasawa A, Susumu N and Aoki D: MicroRNA and endometrial cancer: Roles of small RNAs in human tumors and clinical applications (Review). Oncol Lett 1: 935-940, 2010

6. Ebert MS and Sharp PA: Roles for microRNAs in conferring robustness to biological processes. Cell 149: 515-524, 2012.

7. Hayes J,Peruzzi PP and Lawler S: MicroRNAs in cancer: Biomarkers, functions and therapy. Trends Mol Med 20: 460-469, 2014.

8. Rogers K and Chen X: Biogenesis, turnover, and mode of action of plant microRNAs. Plant Cell 25: 2383-2399, 2013.

9. Liu Y, Yan W, Zhang W, Chen L, You G, Bao Z, Wang Y, Wang H, Kang $\mathrm{C}$ and Jiang T: MiR-218 reverses high invasiveness of glioblastoma cells by targeting the oncogenic transcription factor LEF1. Oncol Rep 28: 1013-1021, 2012.
10. Wang HT, Liu AG, Luo DS, Zhou ZN, Lin HG, Chen RZ, He JS and Chen K: miR-218 expression in osteosarcoma tissues and its effect on cell growth in osteosarcoma cells. Asian Pac J Trop Med 7: 1000-1004, 2014

11. Jin J, Cai L, Liu ZM and Zhou XS: miRNA-218 inhibits osteosarcoma cell migration and invasion by down-regulating of TIAM1, MMP2 and MMP9. Asian Pac J Cancer Prev 14: 3681-3684, 2013.

12. Lukas J, Petersen BO, Holm K, Bartek J and Helin K: Deregulated expression of E2F family members induces S-phase entry and overcomes p16INK4A-mediated growth suppression. Mol Cell Biol 16: 1047-1057, 1996.

13. Infante A, Laresgoiti U, Fernández-Rueda J, Fullaondo A, Galán J, Díaz-Uriarte R, Malumbres M, Field SJ and Zubiaga AM: E2F2 represses cell cycle regulators to maintain quiescence. Cell Cycle 7: 3915-3927, 2008.

14. Muller H, Bracken AP, Vernell R, Moroni MC, Christians F, Grassilli E, Prosperini E, Vigo E, Oliner JD and Helin K: E2Fs regulate the expression of genes involved in differentiation, development, proliferation, and apoptosis. Genes Dev 15: 267-285, 2001.

15. Chen HZ, Tsai SY and Leone G: Emerging roles of E2Fs in cancer: An exit from cell cycle control. Nat Rev Cancer 9: 785-797, 2009.

16. Livak KJ and Schmittgen TD: Analysis of relative gene expression data using real-time quantitative PCR and the 2(-Delta Delta C(T)) method. Methods 25: 402-408, 2001.

17. Wang T, Chen T, Niu H, Li C, Xu C, Li Y, Huang R, Zhao J and Wu S: MicroRNA-218 inhibits the proliferation and metastasis of esophageal squamous cell carcinoma cells by targeting BMI1. Int J Mol Med 36: 93-102, 2015.

18. Sui C, Xu F, Shen W, Geng L, Xie F, Dai B, Lu J, Zhang M and Yang J: Overexpression of miR-218 inhibits hepatocellular carcinoma cell growth through RET. Tumour Biol 36: 1511-1518, 2015.

19. Song L, Li D, Zhao Y, Gu Y, Zhao D, Li X, Bai X, Sun Y, Zhang X, Sun $\mathrm{H}$, et al: miR-218 suppressed the growth of lung carcinoma by reducing MEF2D expression. Tumour Biol 37: 2891-2900, 2015.

20. Liu Z, Xu Y, Long J, Guo K, Ge C and Du R: microRNA-218 suppresses the proliferation, invasion and promotes apoptosis of pancreatic cancer cells by targeting HMGB1. Chin J Cancer Res 27: 247-257, 2015.

21. Jun GJ, Zhong GG and Ming ZS: miR-218 inhibits the proliferation of glioma U87 cells through the inactivation of the CDK6/cyclin D1/p21 pathway. Oncol Lett 9: 2743-2749, 2015.

22. Han G, Fan M and Zhang X: microRNA-218 inhibits prostate cancer cell growth and promotes apoptosis by repressing TPD52 expression. Biochem Biophys Res Commun 456: 804-809, 2015.

23. Cheng Y, Yang X, Deng X, Zhang X, Li P, Tao J and Lu Q: MicroRNA-218 inhibits bladder cancer cell proliferation, migration, and invasion by targeting BMI-1. Tumour Biol 36: 8015-8023, 2015.

24. Fan R, Zhong J, Zheng S, Wang Z, Xu Y, Li S, Zhou J and Yuan F: MicroRNA-218 inhibits gastrointestinal stromal tumor cell and invasion by targeting KIT. Tumour Biol 35: 4209-4217, 2014.

25. Shi J, Yang L, Wang T, Zhang J, Guo X, Huo X and Niu H: miR-218 is downregulated and directly targets SH3GL1 in childhood medulloblastoma. Mol Med Rep 8: 1111-1117, 2013.

26. Iwasaki T, Tanaka $\mathrm{K}$, Kawano M, Itonaga I and Tsumura $\mathrm{H}$ : Tumor-suppressive microRNA-let-7a inhibits cell proliferation via targeting of E2F2 in osteosarcoma cells. Int J Oncol 46: 1543-1550, 2015.

27. Pusapati RV, Weaks RL, Rounbehler RJ, McArthur MJ and Johnson DG: E2F2 suppresses Myc-induced proliferation and tumorigenesis. Mol Carcinog 49: 152-156, 2010.

28. Zhang Y, Han D, Wei W, Cao W, Zhang R, Dong Q, Zhang J, Wang Y and Liu N: MiR-218 inhibited growth and metabolism of human glioblastoma cells by directly targeting E2F2. Cell Mol Neurobiol 35: 1165-1173, 2015.

29. Dong Y, Zou J, Su S, Huang H, Deng Y, Wang B and Li W: MicroRNA-218 and microRNA-520a inhibit cell proliferation by downregulating E2F2 in hepatocellular carcinoma. Mol Med Rep 12: 1016-1022, 2015.

30. Gao Y, Ma X, Yao Y, Li H, Fan Y, Zhang Y, Zhao C, Wang L, Ma M, Lei $Z$ and Zhang $X$ : miR-155 regulates the proliferation and invasion of clear cell renal cell carcinoma cells by targeting E2F2. Oncotarget 7: 20324-20337, 2016.

31. Li T, Luo W, Liu K, Lv X and Xi T: miR-31 promotes proliferation of colon cancer cells by targeting E2F2. Biotechnol Lett 37: 523-532, 2015. 